\title{
Micelle Mediated Trace Level Sulfide Quantification through Cloud Point Extraction
}

\author{
Samrat Devaramani and Pandurangappa Malingappa \\ Department of Studies in Chemistry, Central College Campus, Bangalore University, Dr. Ambedkar Veedhi, Bangalore 560 001, India \\ Correspondence should be addressed to Pandurangappa Malingappa, mprangachem@gmail.com
}

Received 14 October 2011; Accepted 14 December 2011

Academic Editors: L. Gámiz-Gracia and T. Kaneta

Copyright ( $) 2012$ S. Devaramani and P. Malingappa. This is an open access article distributed under the Creative Commons Attribution License, which permits unrestricted use, distribution, and reproduction in any medium, provided the original work is properly cited.

\begin{abstract}
A simple cloud point extraction protocol has been proposed for the quantification of sulfide at trace level. The method is based on the reduction of iron (III) to iron (II) by the sulfide and the subsequent complexation of metal ion with nitroso-R salt in alkaline medium. The resulting green-colored complex was extracted through cloud point formation using cationic surfactant, that is, cetylpyridinium chloride, and the obtained surfactant phase was homogenized by ethanol before its absorbance measurement at $710 \mathrm{~nm}$. The reaction variables like metal ion, ligand, surfactant concentration, and medium $\mathrm{pH}$ on the cloud point extraction of the metal-ligand complex have been optimized. The interference effect of the common anions and cations was studied. The proposed method has been successfully applied to quantify the trace level sulfide in the leachate samples of the landfill and water samples from bore wells and ponds. The validity of the proposed method has been studied by spiking the samples with known quantities of sulfide as well as comparing with the results obtained by the standard method.
\end{abstract}

\section{Introduction}

Sulfide is one of the most essential parameter in monitoring the water quality due to its high toxicity for aquatic life. Dissolved sulfide is toxic to some fresh water fish even at the concentration level less than $1 \mathrm{ppm}$ [1]. The threshold limit value of sulfide in drinking water has been prescribed as $0.05-0.1 \mathrm{ppm}$ by the world health organization (WHO) [2] Sulfide anion is an important constituent of aqueous systems wherever microbial colonies flourish. Because of its toxicity and removal ability of dissolved oxygen, there are limits on the total level of sulfide permitted in waste discharges [3]. Hence, its concentration needs to be controlled especially in water and waste water discharges. Monitoring of aqueous sulfide is one of the important parameters in industrial effluents as the discharges containing sulfide cause the contamination. The treatment of such water generally involves aeration, chlorination or flocculation, and other processes [4]. The treated effluent must meet regulatory specifications before it can be discharged into environment. Thus, it is mandatory to determine sulfide levels during various stages of treatment [5] Although sulfide is currently regarded as a core parameter for assessing environmental quality of a given water system, the clean matrices such as mineral water, biogenic sulfide in natural waters require highly sensitive methods to quantify trace level sulfide with high precision and accuracy [1]. Determination of sulfide in the waste water or the first-stage effluent is a challenging problem due to the complex nature of the matrix. Both petroleum- and kraftprocesses-based paper and pulp industries generate sufficient quantities of sulfide bearing waste water. Sodium sulfide is one of the most widely used reagents for the removal of hair from animal hides with processing liquors possessing sulfide ion concentration up to $2000 \mathrm{ppm}$ [6]. Sulfide gets released into aquatic environments substantially through bacterial mobilization of sulfur containing minerals.

Several methods have been reported for the quantification of dissolved aqueous sulfide. These are mainly based on titrimetric, chromatographic, and spectroscopic techniques. Among these, spectroscopic-related methods have been proved to be important due to its simplicity, selectivity, and sensitivity. Methylene blue method is considered as 
a standard method for the quantification of sulfide due to its sensitivity and easy adoptability. But the method suffers from the interference of thiols, and acidity plays a critical role in the production of phenothiazinium dye.

Several methods have been reported by adopting the same reaction using different analytical techniques like flow injection analysis, solid-phase extraction, and solid-phase reflectometry $[7,8]$. In addition to the spectrophotometry, various other techniques like atomic florescence spectroscopy (AFS) [9], atomic absorption spectroscopy (AAS) [10], flow injection analysis (FIA) $[11,12]$, and inductively coupled plasma atomic emission spectroscopy (ICPAES) [13] have been successfully utilized for the quantification of sulfide. These techniques require expensive instrumentation and skilled technical personnel to operate the systems. Hence, spectrophotometric methods find widespread use due to their simplicity and easy operation in the estimation of sulfide. Organic solvents have been extensively used for the extraction of the metal-ligand complexes in spectrophotometric methods to lower the detection limit and to improve the sensitivity. However, the use of organic solvents is not preferred in recent years due to green protocols as they are toxic in nature. Hence, surfactants have been used as alternative reagents to enhance the sensitivity of the reaction as well as analyte preconcentration in cloud-point-based extraction procedures.

The combination of pronounced hydrophobic and hydrophilic properties within a molecule gives surfactant molecules unique properties on dissolution in water [14]. Surfactants on dissolution in water form organized molecular assemblies called micelles if the critical micelle concentration (CMC) exceeded. Organized molecular assemblies have potential utility in chemical analysis because micelles enhance the solubility of organic compounds in water by providing local nonpolar environment [15]. Watanabe and coworkers have introduced cloud point extraction (CPE) as a promising new separation and extraction technique as an alternative in place of organic solvents [16]. CPE based on the clouding phenomenon of surfactants has become attractive because it offers many advantages over traditional liquidliquid extraction methods. Recently, cloud point extraction of ethylene blue for the estimation of sulfide in water samples has been reported [17].

Neutral surfactants have been extensively used in sensitizing the reactions in various analytical applications. However, use of cationic surfactant as a sensitizing agent has not been explored fully in recent years [18-20]. Here, we are reporting the use of cationic surfactant, that is, cetylpyridinium chloride (CPC), as a sensitizing agent to quantify trace level sulfide by its reaction with ferric iron and its subsequent complexation of reduced ferrous iron with nitroso-R salt to form a green-colored complex. The complex has been quantitatively extracted into surfactant-rich phase in the presence of potassium iodide. The method has been applied for the quantification of dissolved sulfide in the leachate, bore well, and pond water samples, and the results obtained by the proposed method are in good agreement with the standard methylene blue method [21].

\section{Experimental}

2.1. Apparatus. Absorbance measurements were made using Shimadzu Scanning Spectrophotometer (model UV$3101 \mathrm{PC}$ ) using $1 \mathrm{~cm}$ quartz cuvettes. All pH measurements were carried out using a control dynamics digital $\mathrm{pH}$ meter (Model APX 175). All reagents were analytical grade and used without further purification. Distilled water was used throughout the experiment.

2.2. Reagents. Iron (III) solution $(100 \mu \mathrm{g} / \mathrm{mL})$ was prepared by dissolving $0.086 \mathrm{~g}$ of ammonium ferric sulphate dodeca hydrate in few drops of concentrated sulphuric acid and then diluted up to the mark in $100 \mathrm{~mL}$ volumetric flask with distilled water. Sulfide stock solution (1000 ppm) was prepared by dissolving $0.748 \mathrm{~g}$ of $\mathrm{Na}_{2} \mathrm{~S} \cdot 9 \mathrm{H}_{2} \mathrm{O}$ in $100 \mathrm{~mL}$ of water, and the solution was stored in a refrigerator. Working standards were prepared from stock solution by appropriate dilution on the day of use. Nitroso-R salt $(0.1 \%)$ : $100 \mathrm{mg}$ of Nitroso-R salt was dissolved in $100 \mathrm{~mL}$ of water. $\mathrm{Na}_{2} \mathrm{HPO}_{4}(0.2 \mathrm{M})$ was prepared by dissolving $2.82 \mathrm{~g}$ of anhydrous $\mathrm{Na}_{2} \mathrm{HPO}_{4}$ in $100 \mathrm{~mL}$ of water. $\mathrm{KH}_{2} \mathrm{PO}_{4}(0.2 \mathrm{M})$ was prepared by dissolving $2.61 \mathrm{~g}$ anhydrous $\mathrm{KH}_{2} \mathrm{PO}_{4}$ in $100 \mathrm{~mL}$ of water. Disodium ethylenediaminetetraacetic acid [ $\mathrm{Na}_{2}$ EDTA] $(0.01 \mathrm{M})$ was prepared by dissolving $0.372 \mathrm{~g}$ in $100 \mathrm{~mL}$ of water. Cetylpyridinium chloride monohydrate $(1.39 \mathrm{mM})$ was prepared by dissolving $0.05 \mathrm{~g}$ of cetylpyridinium chloride in $100 \mathrm{~mL}$ of water. Potassium iodide (10\%) was prepared by dissolving $10 \mathrm{~g}$ in $100 \mathrm{~mL}$ of water.

2.3. Aqueous Procedure. Aliquots $(0.2-1 \mathrm{~mL})$ of $10 \mu \mathrm{g} / \mathrm{mL}$ sulfide solutions were transferred into a series of $10 \mathrm{~mL}$ volumetric flasks containing $1.5 \mathrm{~mL}$ of $100 \mu \mathrm{g} / \mathrm{mL}$ of $\mathrm{Fe}$ (III) solution. Then $0.5 \mathrm{~mL}$ of $0.1 \%$ nitroso-R salt solution followed by $3 \mathrm{~mL}$ of phosphate buffer ( $\mathrm{pH} 7$ ) was added. The solutions were diluted to the mark with distilled water, and the absorbance values were measured at $710 \mathrm{~nm}$ (Figure 1).

2.4. Extraction Procedure. Aliquots $(0.2-1.8 \mathrm{~mL})$ of $1 \mu \mathrm{g} / \mathrm{mL}$ sulfide solutions were transferred into a series of $10 \mathrm{~mL}$ volumetric flasks containing $1.5 \mathrm{~mL}$ of $100 \mu \mathrm{g} / \mathrm{mL}$ of Fe (III) solution. Then $0.5 \mathrm{~mL}$ of $0.1 \%$ nitroso-R salt solution and $3 \mathrm{~mL}$ of phosphate buffer of $\mathrm{pH} 7$ followed by $1.5 \mathrm{~mL}$ of EDTA were added, and the contents were mixed well. To that $1 \mathrm{~mL}$ of cetylpyridinium chloride followed by $1.5 \mathrm{~mL}$ of potassium iodide, solutions were added. The solutions were diluted to the mark with distilled water, and the contents were mixed well. The reaction mixture has been centrifuged for $6 \mathrm{~min}$ at $4000 \mathrm{rpm}$. The aqueous phase was separated by decantation process, and the micellar phase was homogenized by the addition of ethanol, and its absorbance was measured at $710 \mathrm{~nm}$ (Figure 1).

\section{Results and Discussion}

The proposed method is based on the reduction of ferric ion using sulfide in mild acidic condition and the subsequent complexation of reduced ferrous ion with nitroso-R salt in alkaline medium (Scheme 1). The initial studies were carried 


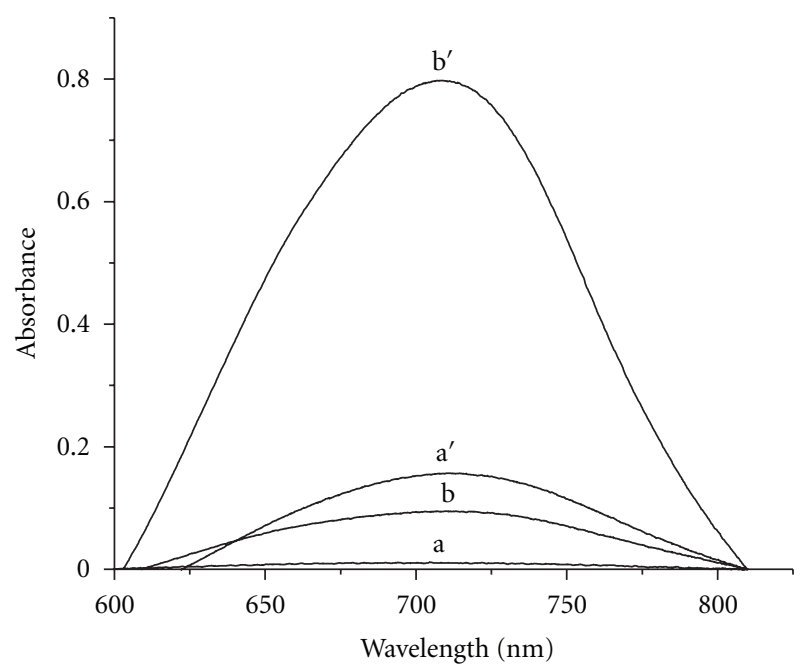

Figure 1: Absorption spectra. $(\mathrm{a}, \mathrm{b})$ are reagent blank and sample absorbance in aqueous phase. $\left(\mathrm{a}^{\prime}, \mathrm{b}^{\prime}\right)$ are reagent blank and sample absorbance in micellar phase.

out using $100 \mu \mathrm{g} / \mathrm{mL}$ of iron (III), $1 \mathrm{~mL}$ each of $0.1 \%$ nitroso$\mathrm{R}$ salt, phosphate buffer ( $\mathrm{pH}$ 7). Absorbance values of the resulting green color complex were measured at $710 \mathrm{~nm}$ and correlated to the concentration of sulfide.

Nitroso-R salt is a sulfonated compound of 1-nitroso2-naphthol, and its metal complexes are easily soluble in water. Because of high water solubility, the Fe (II)-nitroso-R complex cannot be extracted into any organic solvent. To improve the sensitivity and working range of the method, the cloud point extraction has been explored using cationic surfactant as a sensitizer. Cloud point extraction can be used when the target species are hydrophobic in nature. Though the Fe (II)-nitroso-R salt complex is water soluble, it has been successfully extracted into surfactant rich phase, and it can be explained through the following mechanism. When the concentration of surfactant is lower than the CMC, only slightly soluble ion associates can form between anionic ligand and surfactant monomers causing turbidity [14]. Electrostatic interaction between the metal-ligand complex and the cationic surfactant takes place through the negatively charged $\mathrm{SO}_{3}{ }^{-}$group of the ligand and the positively charged head group of the surfactant molecule. The solubilizing effect of the surfactant begins at critical micellar concentration (CMC) and above, hence the neutral complexes gets trapped into the micelles (Figure 2). Once the complex gets incorporated into the micellar core, it becomes easy to separate it from the aqueous phase. Addition of salts to ionic micelle solution reduces the mutual electrostatic repulsions of charged head groups. This leads to an increased aggregation number and micellar diameter. High concentration of salt cause cationic surfactant solutions to separate into immiscible surfactant rich and surfactant-poor phases [22].

3.1. Optimization Study. In order to apply the developed method to quantify the trace level sulfide from a variety of environmental matrices, the reaction variables have been optimized.
3.2. Effect of Iron (III) Ion Concentration. The effect of metal ion concentration on the absorbance of the complex was studied in the concentration range of $25-500 \mu \mathrm{g} / \mathrm{mL}$. The absorbance of the complex Fe (II)-nitroso-R saltcetylpyridinium chloride against reagent blank was measured at $710 \mathrm{~nm}$. The absorbance value increases steadily in the concentration range of $25-100 \mu \mathrm{g} / \mathrm{mL}$ of iron, and there after it remained almost constant as shown in Figure 3. The maximum absorbance was obtained at a concentration of $150 \mu \mathrm{g} / \mathrm{mL}$ of iron (III), and it has been fixed as an optimum concentration and used in all further studies.

3.3. Effect of Nitroso-R Salt. The effect of nitroso-R salt concentration on the extraction of the complex was investigated by varying its concentration by the addition of $0.2-$ $0.8 \mathrm{~mL}$ of $2.6 \mathrm{mM}$ ligand solution. The sensitivity of the method increased with the increasing volume of the ligand as shown in Figure 4. At higher concentrations, there exists a competition between ligand and its iron (II) complex to extract into the surfactant-rich phase, so the concentration of ligand in surfactant-rich phase increased. It resulted in the increase of blank value by suppressing the sample absorbance. Hence, $0.5 \mathrm{~mL}$ of ligand concentration has been optimized to get the maximum sample absorbance with minimum blank.

3.4. Effect of $p H$. The effect of $\mathrm{pH}$ on the formation of metalligand complex was carried out in the $\mathrm{pH}$ range of 7 to 12 as the complexation takes place only in the alkaline condition. The variation of $\mathrm{pH}$ was carried out by using phosphate buffer solutions of different $\mathrm{pH}$ values. The sample absorbance remains almost constant throughout the $\mathrm{pH}$ range studied but the blank absorbance value increased with the increase in the medium $\mathrm{pH}$. In order to get the low blank absorbance value, the medium $\mathrm{pH}$ was maintained in the range of 7-8 (Figure 5). This constant $\mathrm{pH}$ was achieved by the addition of $3 \mathrm{~mL}$ of phosphate buffer to the reaction mixture, and it was optimized and used in all further studies.

3.5. Effect of Surfactant. Surfactants have been used to extract the metal-ligand complexes efficiently without using organic solvents [23]. Hence, an attempt has been made to extract the Fe (II)-nitroso-R salt complex from the aqueous solution using different types of surfactants. These surfactants are known to form aggregates which are called micelles, and these entrap the complexes very efficiently which causes phase separation. Several surfactants have been tried to separate the metal-ligand complex from aqueous phase. After adding surfactant, the solutions were heated to different temperatures to cause cloud point formation. Once clouding takes place, the phase separation can be efficiently carried out by simple centrifugation procedure. Among the surfactants used, Triton X 100 which is a neutral surfactant could not cause any quantitative extraction even after heating to $80^{\circ} \mathrm{C}$. Since the complex is anionic in nature, the use of cationic surfactant may facilitate the quantitative extraction of the metal-ligand complex. Therefore several cationic surfactants were used in order to extract the metal-ligand complex 


$$
2 \mathrm{Fe}^{3+}+\mathrm{S}^{2-} \longrightarrow 2 \mathrm{Fe}^{2+}+\mathrm{S}
$$

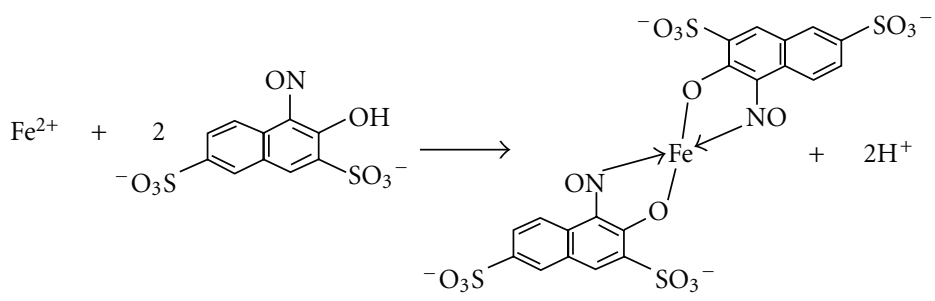

Scheme 1: Species responsible for color formation.

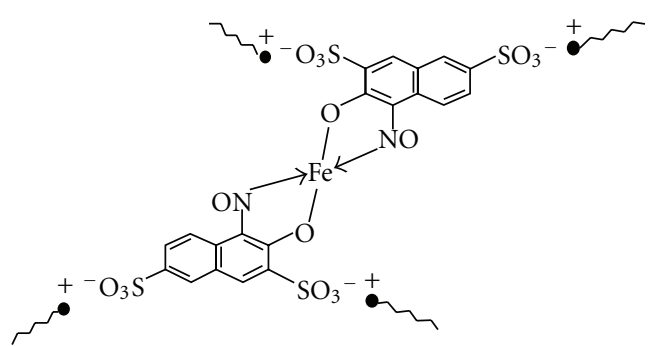

(a)

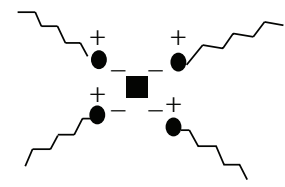

(b)

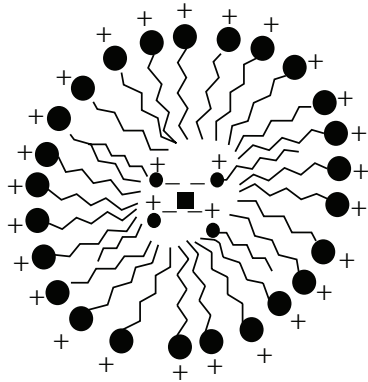

(c)

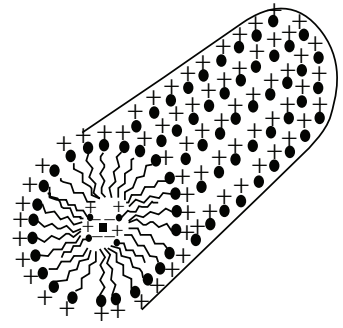

(d)

FIGURE 2: Schematic representation of metal-ligand complex at different stages in the presence of cationic surfactant. (a) Neutralized complex in bulk solution, (b) symbolic representation of electrostatically neutralized complex, (c) incorporation of metal-ligand complex into the hydrophobic core of micelle, and (d) agglomeration of the complex entrapped micelles to form the tubular or rod-like structures.

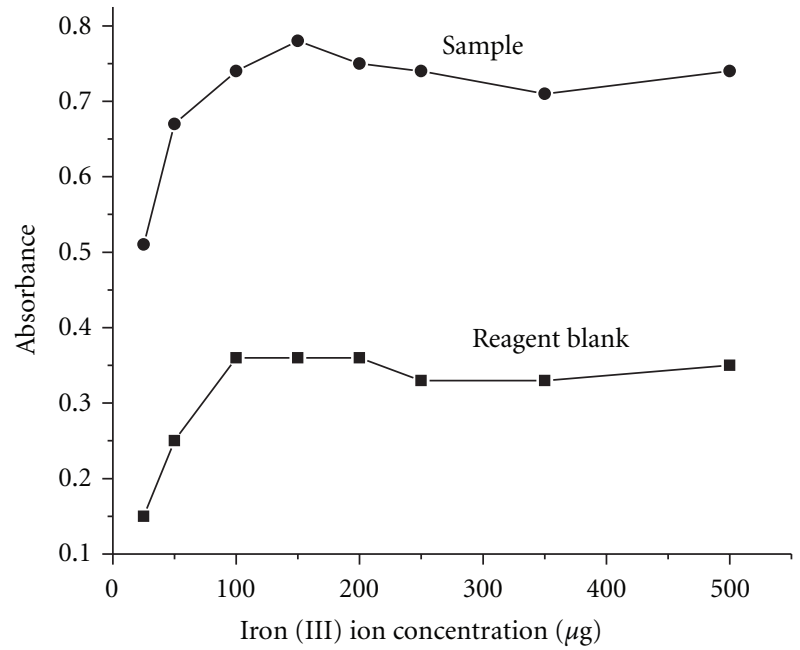

Figure 3: Effect of iron (III) ion.

quantitatively from aqueous phase. The list of the surfactants used for the extraction of the complex is listed in Table 1. Among these, only cationic surfactants could quantitatively extract the $\mathrm{Fe}(\mathrm{II})$-nitroso-R salt complex from aqueous phase. The clouding results at room temperature itself, hence the cationic surfactants have been used in the present investigation. The monomer molecules of the cationic surfactant

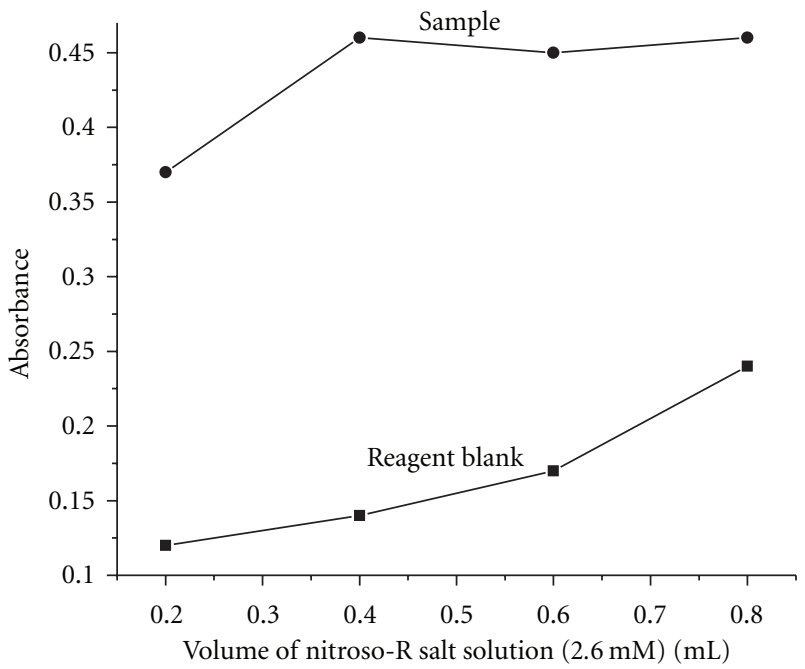

FIgURE 4: Effect of nitroso-R salt.

initially neutralize the anionic complex and form micelles. These formed micelles entrap the complex into its core and undergo clouding at room temperature $\left(27 \pm 2{ }^{\circ} \mathrm{C}\right)$. Among the three cationic surfactants, CPC gave a higher absorbance value to the sample when compared to the other surfactants, hence CPC has been used as a surfactant in all further studies. The effect of CPC concentration on the extraction of 


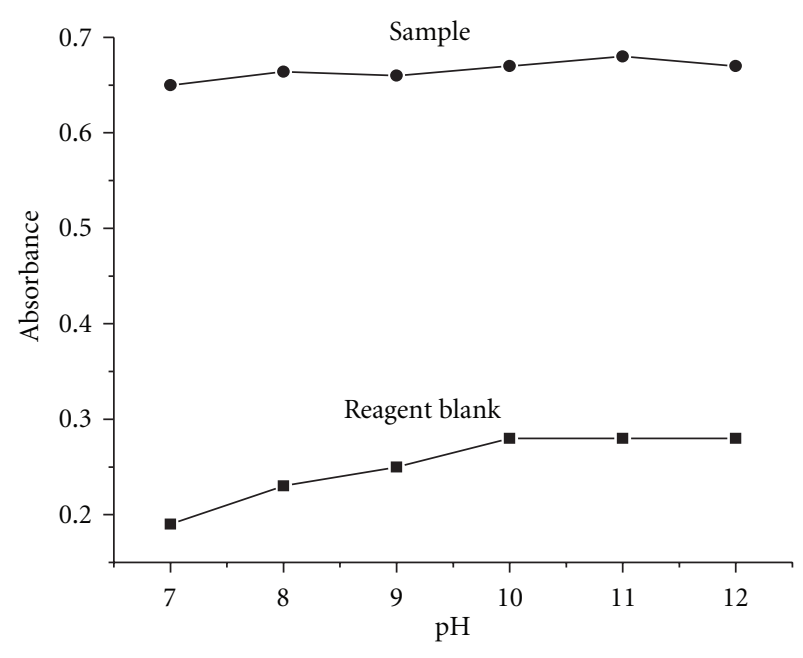

Figure 5: Effect of $\mathrm{pH}$.

TABLE 1: Effect of surfactant.

\begin{tabular}{lcc}
\hline $\begin{array}{l}\text { Surfactant } \\
\text { type }\end{array}$ & $\begin{array}{c}\text { Sample v/s blank } \\
\text { Absorbance after CPE }\end{array}$ & Temperature $\left({ }^{\circ} \mathrm{C}\right)$ \\
\hline $\begin{array}{l}\text { None } \\
\text { Triton X100 }\end{array}$ & 0.08 & RT \\
CTAB & No extraction & 80 \\
CPC & 0.50 & RT \\
Cetrimide & 0.56 & RT \\
\hline
\end{tabular}

RT-room temperature; $\mathrm{CTAB}$ - cetyl trimethyl ammonium bromide, CPC-cetylpyridinium chloride.

the complex was investigated by varying its concentration by the addition of $0.6-1.0 \mathrm{~mL}$ of $1.39 \mathrm{mM}$ solution. Extraction has not been observed below $0.6 \mathrm{~mL}$ of the surfactant. Extraction of the complex increased with the increase in concentration up to $1 \mathrm{~mL}$; thereafter sample absorbance value almost remained constant (Figure 6). Hence, $1 \mathrm{~mL}$ of $1.39 \mathrm{mM}$ concentration of the surfactant has been fixed as the optimum value where the absorbance of the sample was high with low blank.

3.6. Effect of Electrolyte. Separation of charged micelles from the aqueous phase can be improved by adding ionic salts like $\mathrm{NaCl}, \mathrm{KI}$, and so forth. High concentration of salt causes cationic surfactant solutions to separate into immiscible surfactant-rich and surfactant-poor phases. Different volumes, that is, $1-2.5 \mathrm{~mL}$, of $10 \% \mathrm{KI}$ solutions were used to study the effect of concentration of the salt on the extraction of the complex in the presence of cationic surfactant, cetylpyridinium chloride. No quantitative extraction was observed in the absence of KI. The complete extraction was caused with the increase in the concentration of the KI (Figure 7). There is a decrease in the absorbance values of both the blank and the sample above $1.5 \mathrm{~mL}$ of $\mathrm{KI}$, and hence an optimum volume of $1.5 \mathrm{~mL}$ of $10 \%$ KI has been used in all further studies to get the low blank and high sample absorbance values.

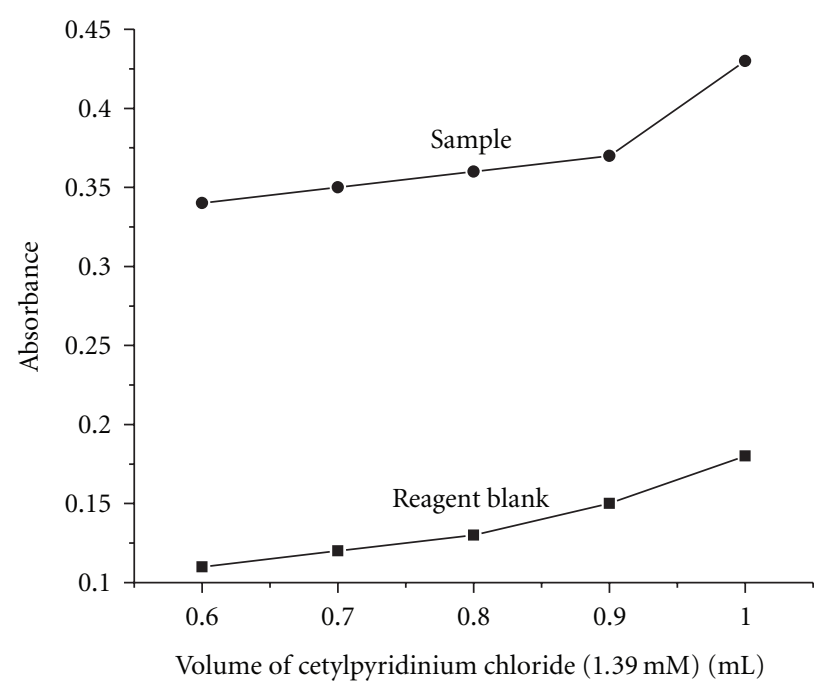

Figure 6: Effect of cetylpyridinium chloride.

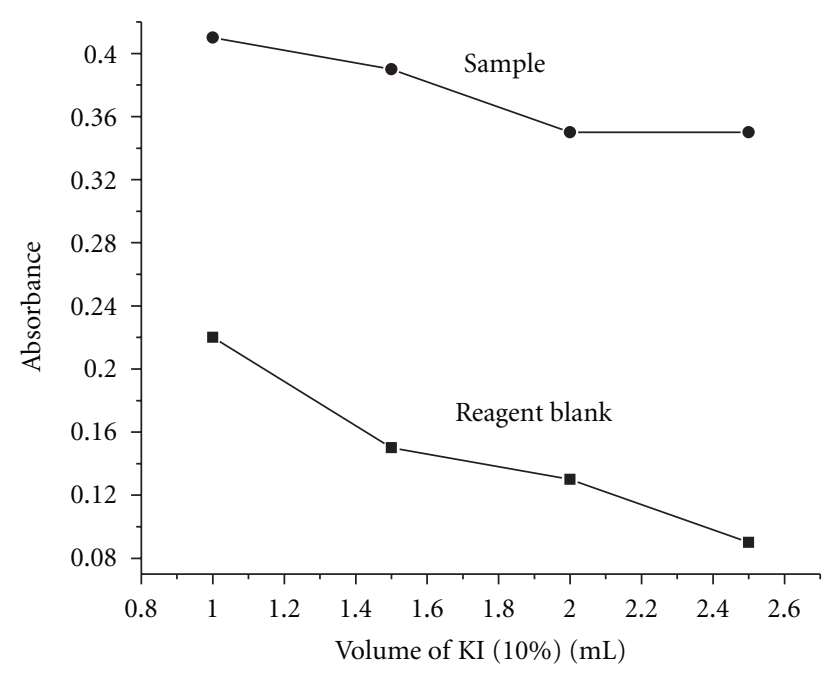

FIGURE 7: Effect of KI on the extraction of metal-ligand complex.

3.7. Effect of EDTA Concentration. Addition of EDTA suppresses the blank absorbance value by masking the excess of unreacted iron (III). Therefore, EDTA was used to lower the blank absorbance value. The EDTA concentration was varied in the concentration range of $0.5-3.0 \mathrm{~mL}$. In the absence of EDTA, the blank value was very high, and it decreased with the rise in the concentration of the masking agent (Figure 8). Hence, $1.5 \mathrm{~mL}$ of $0.02 \mathrm{M}$ EDTA has been used as an optimum concentration in all further studies to obtain the maximum sample absorbance with low blank value.

3.8. Effect of Centrifugation Time. The effect of centrifugation time for the efficient phase separation was examined by centrifuging the resulting cloud phase at $4000 \mathrm{rpm}$ at different time intervals of $2-8 \mathrm{~min}$. Beyond five minutes, the absorbance values of the complex have remained constant. Hence, six-minute time has been fixed as the optimum centrifugation time. 


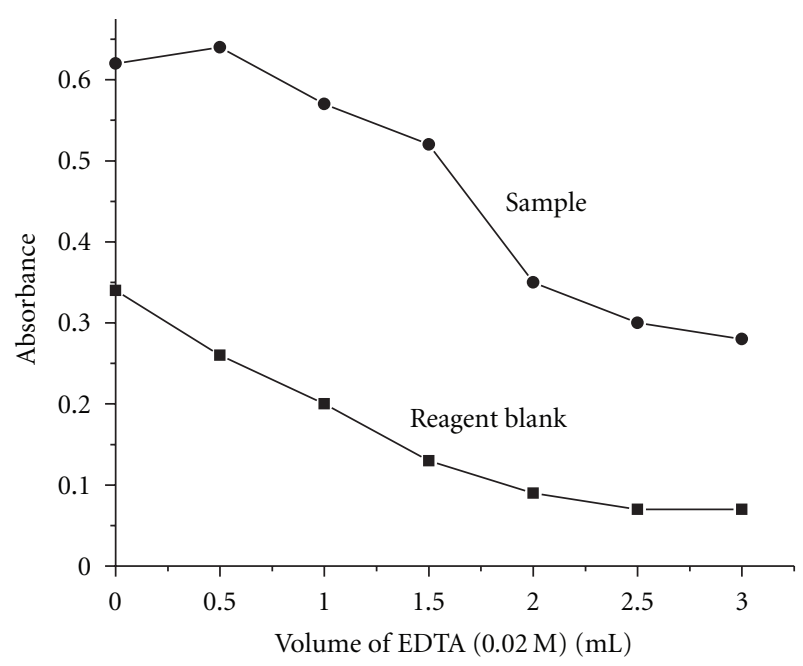

FIgURE 8: Effect of EDTA.

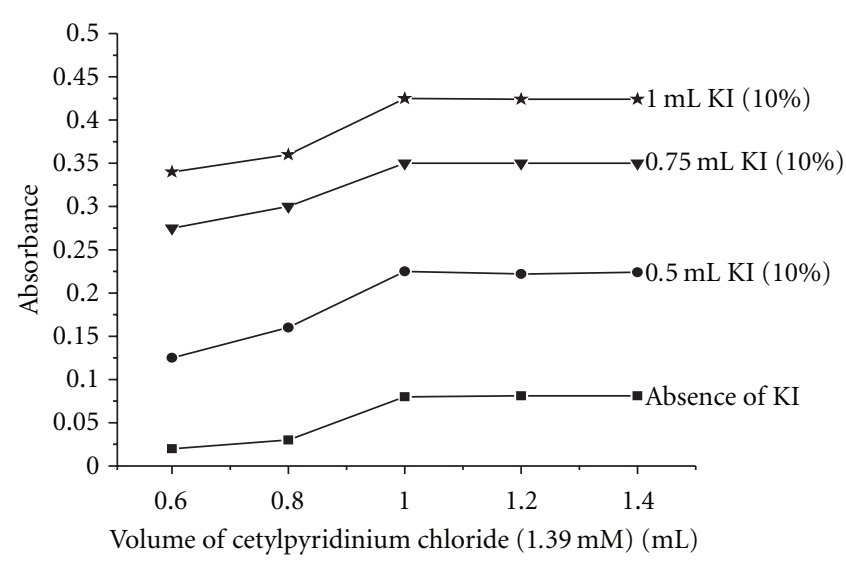

FIgURE 9: Phase diagram of the CPC, water, and KI ternary system.

3.9. Phase Diagram. The influence of electrolyte added, that is, $\mathrm{KI}$ [ 0.5 to $1.0 \mathrm{~mL}$ of $10 \%$ ] on the extraction of Fe (II)nitroso-R salt complex was examined at various cetylpyridinium chloride concentrations in the range from 0.6 to $1.4 \mathrm{~mL}$ of $1.39 \mathrm{mM}$. It is evident from Figure 9 that the extent of extraction has been increased in the presence of higher concentrations of KI. This behavior can be explained in terms of faster dehydration of surfactant molecules due to the presence of inorganic ions (here $\mathrm{K}^{+}$and $\mathrm{I}^{-}$) competing for interaction with water molecules, that is, a "salting out effect."

3.10. Analytical Figures of Merit. A simple cloud point extraction method has been developed for the quantification of dissolved sulfide using nitroso- $\mathrm{R}$ salt in the presence of cetylpyridinium chloride. The analytical figures such as $\lambda_{\max }$, molar absorption coefficient, and detection limit of the method were found to be $710 \mathrm{~nm}, 5.66 \times 10^{4}$, and $0.0002 \mu \mathrm{g} / \mathrm{mL}$, respectively. Beer's law is valid in the concentration range $0.02-0.18 \mu \mathrm{g} / \mathrm{mL}$ of the analyte. The calibration graph has been obtained with a regression equation $0.168+$ $0.500 \mathrm{X}$ and the correlation coefficient $(\mathrm{R}) 0.9997$. The relative
TABLE 2: Interference study.

\begin{tabular}{lc}
\hline Interfering ion & $\begin{array}{c}\text { Tolerance limit } \\
(\mu \mathrm{g})\end{array}$ \\
\hline $\mathrm{Cl}^{-}$ & $>1000$ \\
$\mathrm{SO}_{3}{ }^{2-}$ & 10 \\
$\mathrm{SO}_{3}{ }^{2-\mathrm{a}}$ & 100 \\
$\mathrm{NO}_{2}{ }^{-}$ & 20 \\
$\mathrm{NO}_{2}{ }^{-\mathrm{b}}$ & 100 \\
$\mathrm{NO}_{3}{ }^{-}$ & 1000 \\
$\mathrm{SO}_{4}{ }^{2-}, \mathrm{CO}_{3}{ }^{2-}$ & $>200$ \\
$\mathrm{I}^{-}, \mathrm{PO}_{4}{ }^{3-}$ & 400 \\
$\mathrm{Zn}^{2+}, \mathrm{Ca}^{2+}$, & $>200$ \\
$\mathrm{Cu}^{2+}, \mathrm{Ni}^{2+}$ & 25 \\
$\mathrm{~Pb}^{2+}$ & 200 \\
$\mathrm{Cd}^{2+}$ & 50 \\
$\mathrm{Mg}^{2+}$ & 600 \\
$\mathrm{Co}^{2+}$ & 05 \\
$\mathrm{HCHO}^{2+}$ & $>1000$ \\
\hline
\end{tabular}

a. Sample was treated with $1 \mathrm{~mL}$ of formaldehyde $(1000 \mu \mathrm{g} / \mathrm{mL})$.

b. Sample was treated with $5 \mathrm{~mL}$ of $0.5 \%$ sulfamic acid.

standard deviation has been found to be 0.0097 for 10 determinations at $1 \mu \mathrm{g}$ level. The preconcentration factor and improvement factors were found to be 5 and 5.7, respectively, in the proposed method.

3.11. Interference Study. The effect of foreign ions has been studied in order to apply the developed method to determine sulfide in aqueous environments. The tolerance limits of different cations and anions have been shown in Table 2. No significant interference has been observed from the common cations and anions except from sulfite and cobalt. Sulfite interfered even at $10 \mu \mathrm{g} / \mathrm{mL}$ level due to its reducing property. The interference of sulfite can be overcome upto $100 \mu \mathrm{g} / \mathrm{mL}$ by the addition of $1000 \mu \mathrm{g}$ of formaldehyde which forms the hydroxymethane sulfonic acid adduct. Formaldehyde did not interfere even at $1000 \mu \mathrm{g}$ level; hence it has been used as a masking agent for sulfite. Nitroso-R salt is a well-known ligand for metal ions like $\mathrm{Fe}, \mathrm{Co}, \mathrm{Ni}, \mathrm{Cu}$, and so forth. Cobalt forms an orange-colored complex with nitroso-R salt solution under the optimized conditions and interfered at $5 \mu \mathrm{g} / \mathrm{mL}$. Other metal ions like mercury, lead, and copper did not interfere. Nitrite interfered at $20 \mu \mathrm{g} / \mathrm{mL}$ and has been overcome by adding $1 \mathrm{~mL}$ of $0.5 \%$ sulfamic acid up to $100 \mu \mathrm{g} / \mathrm{mL}$. The addition of sulfamic acid to the reaction mixture minimizes nitrite interference. Other anions like sulphate, phosphate, iodide, carbonate, chloride, and nitrate did not interfere significantly in the proposed method.

3.12. Application to Environmental Samples. Water passing through the landfill which collects the dissolved and suspended matter from it is called leachate. Generally, leachate may contain nitrate, phosphate, organic matter and sulfide, and so forth in significant quantities [24]. Solid wastes placed in a sanitary landfill may undergo a number of biological, chemical, and physical changes. Aerobic and anaerobic 
TABLE 3: Determination of dissolved sulfide from leachate samples.

\begin{tabular}{|c|c|c|c|c|c|c|c|}
\hline \multirow[b]{2}{*}{ Sample } & \multicolumn{2}{|c|}{ Sulfide found (ppm) } & \multirow{2}{*}{$\begin{array}{l}\text { Sulfide added } \\
\quad(\mathrm{ppm})\end{array}$} & \multicolumn{2}{|c|}{ Total sulfide (ppm) } & \multicolumn{2}{|c|}{ Recovery of added sulfide (\%) } \\
\hline & $\begin{array}{c}\text { Proposed } \\
\text { method }\end{array}$ & $\begin{array}{c}\text { Standard } \\
\text { method }\end{array}$ & & $\begin{array}{c}\text { Proposed } \\
\text { method }\end{array}$ & $\begin{array}{c}\text { Standard } \\
\text { method }\end{array}$ & $\begin{array}{c}\text { Proposed } \\
\text { method }\end{array}$ & $\begin{array}{c}\text { Standard } \\
\text { method }\end{array}$ \\
\hline $\mathrm{A}^{*}$ & $2.81 \pm 0.37$ & $2.88 \pm 0.12$ & - & - & - & - & - \\
\hline $\mathrm{B}^{*}$ & $1.94 \pm 0.28$ & $1.90 \pm 0.15$ & 1.0 & $2.86 \pm 0.22$ & $2.91 \pm 0.09$ & 99.31 & 102.34 \\
\hline $\mathrm{C}^{*}$ & $1.03 \pm 0.21$ & $1.05 \pm 0.12$ & 2.0 & $3.00 \pm 0.18$ & $3.08 \pm 0.10$ & 99.00 & 102.98 \\
\hline $\mathrm{D}^{*}$ & ND & ND & 1.0 & $1.03 \pm 0.20$ & $1.02 \pm 0.09$ & 103.00 & 102.00 \\
\hline $\mathrm{D}^{* *}$ & ND & ND & 1.0 & $1.09 \pm 0.18$ & $1.02 \pm 0.11$ & 109.00 & 102.00 \\
\hline
\end{tabular}

Values given here are the average of three measurements \pm RSD.

ND- not detected.

* Sulfide determined by aqueous procedure.

** Sulfide determined by cloud point extraction procedure.

TABLE 4: Determination of dissolved sulfide from bore well and pond water samples using extraction procedure.

\begin{tabular}{lcccc}
\hline Sample & Sulfide found $(\mathrm{ppm})$ & Sulfide added $(\mathrm{ppm})$ & Total sulfide $(\mathrm{ppm})$ & Recovery of added sulfide $(\%)$ \\
\hline $\mathrm{A}^{\mathrm{a}}$ & $0.297 \pm 0.037$ & 0.5 & $0.810 \pm 0.033$ & 101.6 \\
$\mathrm{~B}^{\mathrm{a}}$ & $0.475 \pm 0.028$ & - & - & - \\
$\mathrm{A}^{\mathrm{b}}$ & $0.139 \pm 0.030$ & 0.5 & $0.661 \pm 0.036$ & 103.4 \\
$\mathrm{~B}^{\mathrm{b}}$ & $0.636 \pm 0.030$ & - & - & - \\
\hline
\end{tabular}

Values given here are the average of three measurements \pm RSD.

a Water samples were collected from bore wells located near the dump sites.

${ }^{\mathrm{b}}$ Water samples were collected from ponds located near the dump sites.

decomposition of the organic matter results in both gaseous and liquid products. Sanitary landfills are one of the important sources of groundwater contamination. Other sources include septic tanks, mining and agricultural activities, and leaking underground storage tanks. In all cases, the threat of contamination to ground water depends on the specific geological and hydrological conditions of the site. Leaking chemicals pass through the soil to the ground water system.

The developed method has been applied to determine trace level sulfide concentrations from the leachate samples as well as water samples collected from the ponds and the bore wells located near the landfills. Known quantities of sulfide were added, and the recovery studies have been carried out to validate the method.

The leachate and water samples collected were filtered using Whatman filter paper to remove any suspended and colloidal particulate matter. $20 \mathrm{~mL}$ of the filtered sample was taken in $25 \mathrm{~mL}$ volumetric flask, and $1 \mathrm{~mL}$ of formaldehyde $(1000 \mu \mathrm{g} / \mathrm{mL})$ was added followed by $1 \mathrm{~mL}$ of sulfamic acid $(0.5 \%)$. The sample was diluted to the mark, and the analysis was carried out by taking $3 \mathrm{~mL}$ aliquot of sample following the procedure described above. The samples were spiked with known amounts of sulfide, and the recovery of sulfide added was studied by the proposed method as well as standard method [25]. The results obtained by the proposed method are in good agreement with the standard method (Tables 3 and 4).

\section{Conclusions}

The proposed micelle mediated cloud point extraction procedure for the determination of trace quantities of dissolved aqueous sulfide is simple, sensitive, and carried out at ambient temperature using cetylpyridinium chloride as a cationic surfactant. No major interferences from the common cations and anions have been found. The proposed method does not require any organic solvent for the extraction purpose, and it has been applied to determine trace level sulfide in leachate samples and water samples. The results obtained by the proposed method are in good agreement with the standard method. It can serve as an alternative to the existing methods.

\section{Acknowledgment}

The authors acknowledge the Council of Scientific and Industrial Research (CSIR), New Delhi, INDIA for the financial support and award of the Senior Research Fellowship (SRF) to S. Devaramani.

\section{References}

[1] S. Gorji and M. Bahram, "Experimental design for the study and optimization of the effect of different surfactants on the spectrophotometric determination of sulfide based on phenothiazine dye production," Analytical Methods, vol. 2, no. 7, pp. 948-953, 2010.

[2] R. J. Cassella, L. S. G. Teixeira, S. Garrigues, A. C. Spinola Costa, R. E. Santelli, and M. De la Guardia, "Determination of sulfide in waters by flow-injection solid phase spectrophotometry," The Analyst, vol. 125, no. 10, pp. 1835-1838, 2000.

[3] Guidelines for Drinking Water Quality, Health Criteria and Other Supporting Information, vol. 2, WHO, Geneva, Switzerland, 2nd edition, 1996. 
[4] S. A. Rahim, A. Y. Salim, and S. Shereef, "Absorptiometric determination of trace amounts of sulphide ion in water," The Analyst, vol. 98, no. 1173, pp. 851-856, 1973.

[5] N. S. Lawrence, J. Davis, and R. G. Compton, "Analytical strategies for the detection of sulfide: a review," Talanta, vol. 52, no. 5, pp. 771-784, 2000.

[6] J. Font, J. Gutiérrez, J. Lalueza, and X. Pérez, "Determination of sulfide in the leather industry by capillary electrophoresis," Journal of Chromatography A, vol. 740, no. 1, pp. 125-132, 1996.

[7] L. Ferrer, J. M. Estela, and V. Cerdà, "A smart multisyringe flow injection system for analysis of sample batches with high variability in sulfide concentration," Analytica Chimica Acta, vol. 573-574, pp. 391-398, 2006.

[8] L. Ferrer, M. Miró, J. M. Estela, and V. Cerdà, "Analytical methodologies for reliable sulfide determinations in aqueous matrices exploiting flow-based approaches," $\operatorname{Tr} A C$, vol. 26, no. 5, pp. 413-422, 2007.

[9] Y. Jin, H. Wu, Y. Tian, L. Chen, J. Cheng, and S. Bi, "Indirect determination of sulfide at ultratrace levels in natural waters by flow injection on-line sorption in a knotted reactor coupled with hydride generation atomic fluorescence spectrometry," Analytical Chemistry, vol. 79, no. 18, pp. 7176-7181, 2007.

[10] A. Afkhami and L. Khalafi, "Indirect determination of sulfide by cold vapor atomic absorption spectrometry," Microchimica Acta, vol. 150, no. 1, pp. 43-46, 2005.

[11] J. C. C. Santos, E. B. G. N. Santos, and M. Korn, "A comparison of flow injection methods for sulfide determination based on phenothiazine dyes produced from diverse aromatic amines," Microchemical Journal, vol. 90, no. 1, pp. 1-7, 2008.

[12] F. Maya, J. M. Estela, and V. Cerdà, "Improving the chemiluminescence-based determination of sulphide in complex environmental samples by using a new, automated multi-syringe flow injection analysis system coupled to a gas diffusion unit," Analytica Chimica Acta, vol. 601, no. 1, pp. 87-94, 2007.

[13] M. Colon, J. L. Todolí, M. Hidalgo, and M. Iglesias, "Development of novel and sensitive methods for the determination of sulfide in aqueous samples by hydrogen sulfide generationinductively coupled plasma-atomic emission spectroscopy," Analytica Chimica Acta, vol. 609, no. 2, pp. 160-168, 2008.

[14] R. P. Paradkar and R. R. Williams, "Micellar colorimetric determination of dithizone metal chelates," Analytical Chemistry, vol. 66, no. 17, pp. 2752-2756, 1994.

[15] E. Pelizzetti and E. Pramauro, "Analytical applications of organized molecular assemblies," Analytica Chimica Acta, vol. 169, pp. 1-29, 1985.

[16] J. Miura, H. Ishii, and H. Watanabe, "Extraction and separation of nickel chelate of 1- (2-thiozolylazo)-2-naphthol in nonionic surfactant solution," Bansuki Kagaku, vol. 25, pp. 808-809, 1976.

[17] A. Afkhami and R. Norooz-Asl, "Cloud point extraction and spectrophotometric determination of sulfide in water samples using ethylene blue formation reaction," Separation Science and Technology, vol. 44, no. 4, pp. 983-994, 2009.

[18] E. K. Paleologos, C. D. Stalikas, S. M. Tzouwara-Karayanni, and M. I. Karayannis, "Selective speciation of trace chromium through micelle-mediated preconcentration, coupled with micellar flow injection analysis-spectrofluorimetry," Analytica Chimica Acta, vol. 436, no. 1, pp. 49-57, 2001.

[19] T. Saitoh and W. L. Hinze, "Use of surfactant-mediated phase separation (cloud point extraction) with affinity ligands for the extraction of hydrophilic proteins," Talanta, vol. 42, no. 1, pp. 119-127, 1995.
[20] A. Afkhami, T. Madrakian, and H. Siampour, "Flame atomic absorption spectrometric determination of trace quantities of cadmium in water samples after cloud point extraction in Triton X-114 without added chelating agents," Journal of Hazardous Materials, vol. 138, no. 2, pp. 269-272, 2006.

[21] M. E. D. Garcia and A. Sanz-Medel, "Dye-surfactant interactions: a review," Talanta, vol. 33, no. 3, pp. 255-264, 1986.

[22] A. E. Vassiliades, Cationic Surfactants, Marcel Dekker, New York, NY, USA, 1970.

[23] M. de Almeida Bezerra, M. A. Zezzi Arruda, and S. L. Costa Ferreira, "Cloud point extraction as a procedure of separation and pre-concentration for metal determination using spectroanalytical techniques: a review," Applied Spectroscopy Reviews, vol. 40, no. 4, pp. 269-299, 2005.

[24] M. L. Davis and D. A. Cornwell, Introduction to Environmental Engineering, McGraw-Hill, London, UK, 1991.

[25] J. P. Lodge, Methods of Air Sampling and Analysis, Lewis, Chelsea, Mich, USA, 1989. 


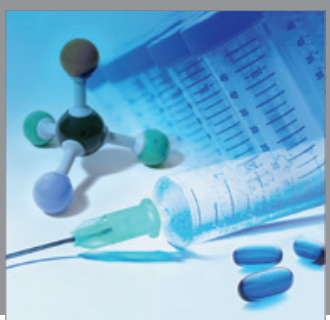

International Journal of

Medicinal Chemistry

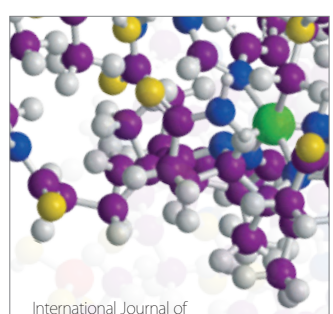

Carbohydrate Chemistry

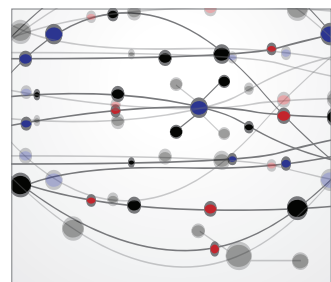

The Scientific World Journal
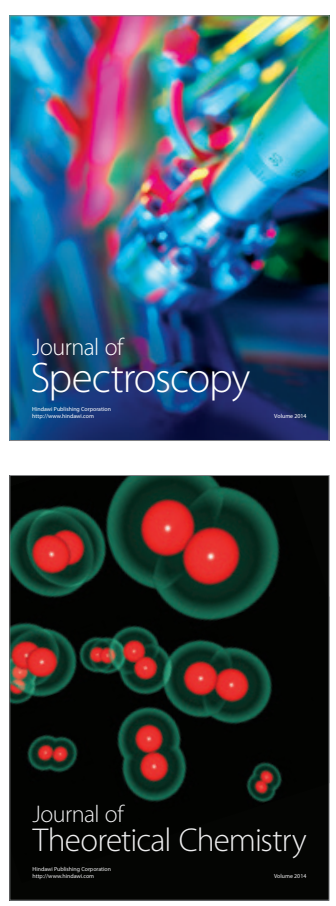
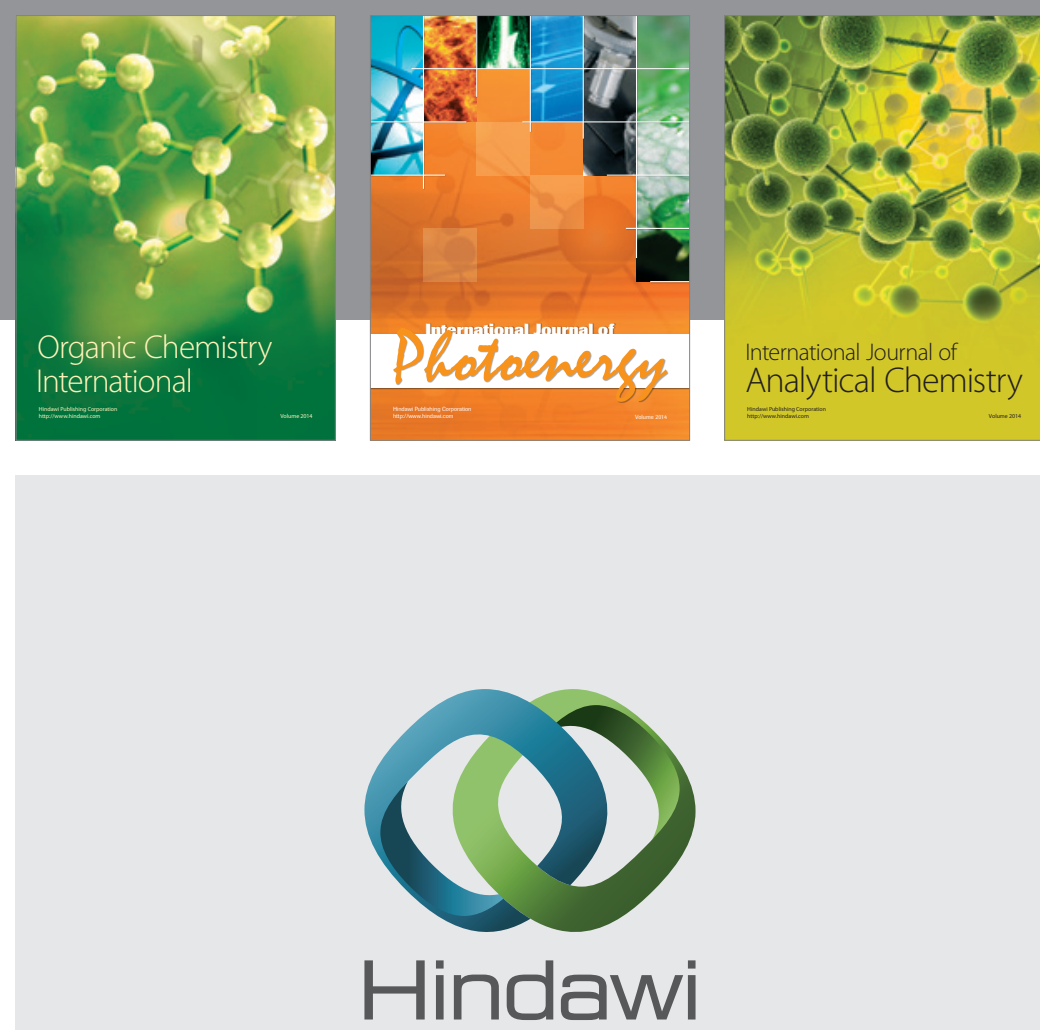

Submit your manuscripts at

http://www.hindawi.com
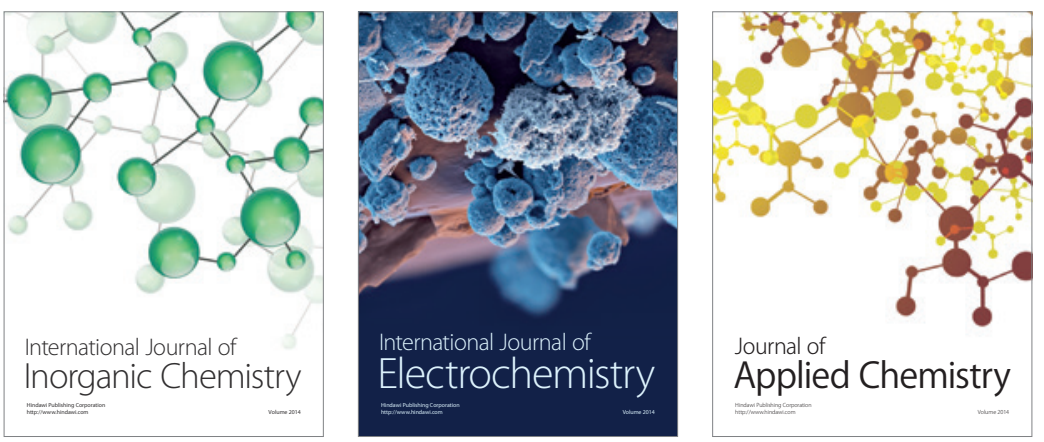

Journal of

Applied Chemistry
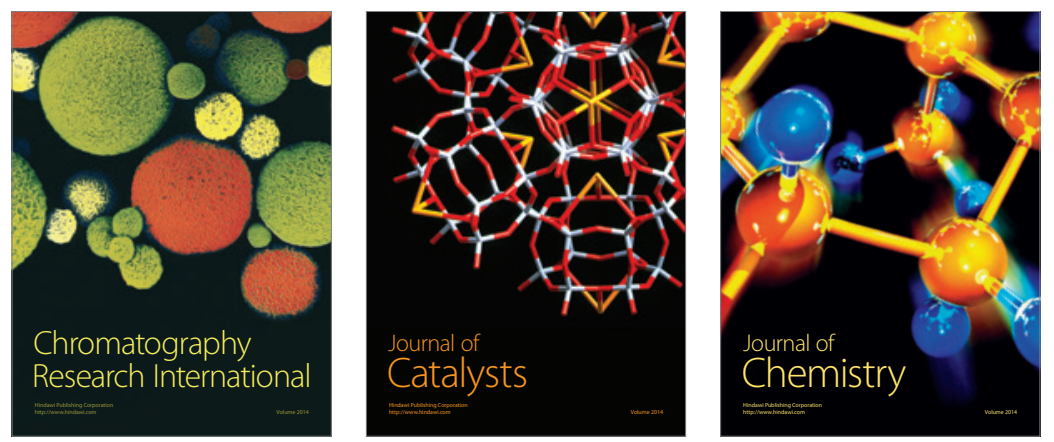
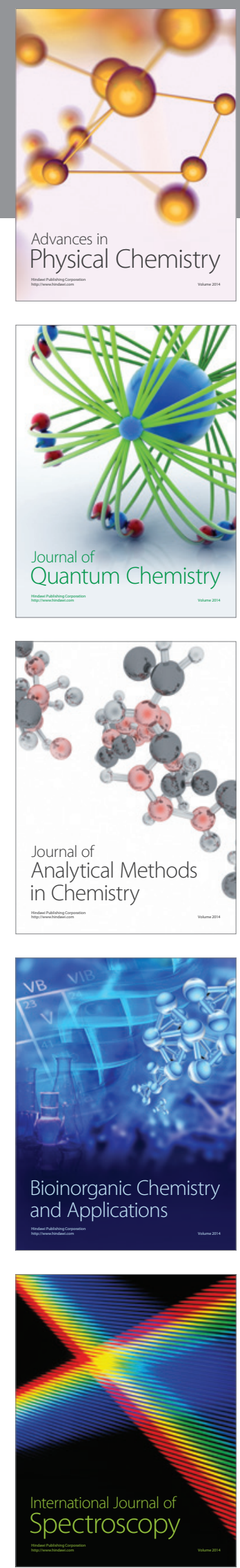